\title{
Economic and technological criteria of choosing the support for construction of mine workings
}

Song Weijie ${ }^{1}$, Pershin V.V. ${ }^{2}$, Masaev Yu. A. ${ }^{2}$, Masaev V.Yu. ${ }^{3}$, Qiao Weiguo ${ }^{1}$

1. College of Civil Engineering and Architecture, Shandong University of Science and Technology, Qingdao, Shandong 266510, China; 2.Department of underground structure and mine construction, Mining Institute of T.F. Gorbachev Kuzbass State

Technical University, 650000, Kemerovo, Russia; 3.Department of enterprise economy and management, G.V. Plekhanov Russian Economic University, Kemerovo Institute, 650000, Kemerovo, Russia

\begin{abstract}
The problems of rock outcrop self-sustainability maintenance in mine construction are considered. The basic requirements to the applied types of supports are formulated. The new design solutions for some kinds of supports are proposed.
\end{abstract}

Keywords: mine opening; support; sustainability; rock outcrops; bolt; roof collapse.

\section{Introduction}

Rockmass is the concentration of various mechanical processes that depend on a number of factors. A feature of such processes affecting mining is the increase of stresses in the marginal rock mass after its mining. The certain values of those stresses being achieved, the marginal rock mass begins to failure losing its bearing capacity. Loss of bearing capacity may occur both as a result of the carrier plastic flow, and as a result of brittle rock fracture.

Mechanical processes that occur in the marginal rock mass often lead to unintended consequences in the form of rock collapse into the working and some geodynamic phenomena. Such processes have repeatedly occurred in coal mines.
To make the reasoned choice of ways and means to prevent these phenomena it is necessary to estimate the degree of development of mechanical processes in the specific geomechanical conditions.

One of the major problems of rock mechanics is the prediction, evaluation and control of self-sustainability of rock outcrops during construction of mine workings.

\section{Characteristic of the work}

Predicting the stability of unsupported mine working at the deterministic formulation of the problem is reduced to the verification of the condition:

$$
\sigma_{\partial}-\sigma_{c \varkappa} \leq 0
$$

wherein $\sigma_{\partial}$ - the main maximum stress, acting at the unsupported contour of the

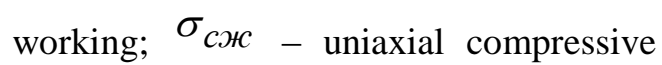
rock resistance.

The various variants of this condition are associated either with the specification of values $\sigma_{\partial}{ }_{\text {и }} \sigma_{\text {сж }}$, for which whole system of rates reflecting various factors is used, or with different ways of comparing the stresses and strength properties of rocks. When the specified condition is fulfilled the outcrop is classified as self-sustainable. A failure of 
this condition is due to the limit equilibrium area formation in the working vicinity and the rock outcrop is considered as unsustainable. On the basis of this condition, various authors have developed a series of numerical criteria which allow classifying the rock outcrops according to the self-sustainability degree.

The self-sustainability of outcrops is strongly influenced, under otherwise equal conditions, by the properties of the host rocks and their water content. Studies conducted in the $700 \mathrm{~m}$ length airway of "Raspadskaya" mine (Kuzbass) with $13.3 \mathrm{~m}^{2}$ cross-sectional area, in the adjacent areas of dry and water-flooded rocks showed the following.

The water intrusion into the seam roof rocks leads to a sharp decrease of the outcrop self-sustainability, intense stratification and rock fall. Flooded and wet roof rocks usually lose self-sustainability in 1-3 hours after their outcropping on the area of 2.5-3.0 $\mathrm{m}^{2}$, while the dry rocks, under otherwise equal conditions, maintain self-sustainability within 24-30 hours or more.

Rock falls occurred unevenly along the exposed surface, they were most often observed in the middle part of the roof and near the sides of the working. The depth of the rock falls since the moment of their outcropping up to time of the support setting ranged from 0.1 to $0.4 \mathrm{~m}$, the area of rock falls - from 0.2 to $0.4 \mathrm{~m}^{2}$. In the course of mining operation the number of rock falls increase, which leads to the destruction of supports and the sufficient size doming, the elimination of which leads to significant economic costs.
On the basis of carried out laboratory and field studies the classification of roof rocks in the workings located outside the area influenced by mining operations was developed.

The classification is based upon the values of the outcrop area and the duration of its self-sustainable state, because these parameters have the greatest influence on the choice of the support type and the justification of timbering plan. According to these criteria the roof rocks of constructed mine workings were divided into seven groups: I - very self-sustainable; II self-sustainable; III - above average self-sustainability; IV - average self-sustainability; V - below average self-sustainability; VI - self-unsustainable; VII - very self-unsustainable.

The developed classification allows: 1) to solve problems of the possibility and necessity of mining operations without or with timbering; 2) to find out the detachment of permanent support from the coal face, which is extremely important when mining under high-speed schedules; 3) to solve the problem of the necessity of protective support application in the face space of workings; 4) to pre-choose the type of permanent support in the workings.

The existing methods used to ensure the mining working sustainability can be divided into three groups depending on the nature of their influence on the mechanical condition of rock mass: active (protection); passive (support) and combined (maintenance). The main way to ensure the self-sustainability of mining workings is the support.

In this regard, a special attention is paid 
to the correct choice of support for different geological conditions. The support of mine working should be integrated with the surrounding rock mass and have adequate ductility and bearing capacity. However, all these conditions are not always met. The analysis shows the common use of such support kinds which have become traditional for certain mines and they are often applied, because the employees of these mines already accustomed to them. But they are not always cost efficient and do not always correspond geological conditions. At the same time, workings conducted through self-sustainable rocks are sometimes supported by unreasonably expensive linings.

One effective means of radical solutions to the problem of rational support and maintenance of mine workings is a combination of load bearing supports and supports which allow using, in varying degrees, the bearing capacity of the rock mass by creating a uniform system of "support - rock mass." Using the rock mass as a load-bearing structure, it is possible to reduce the material intensity and the cost of supports, without losing the self-sustainability of the working. From an economic point of view it is necessary to be guided on the use of lightweight types of supports, but the final choice should obviously be based on its reliability.

A very important factor is the quality of marking the working contour during its construction. If the contour of the working is uneven (as in the case of drilling and blasting method of mining), the stress concentration around the working will be completely different from that of the smooth contour (as in the case of cutting method). However, the rocks destroyed by explosion, although less stable and exposed to larger displacements then the solid rocks in the course of rock mass deformation (due to loosening effect), are discharged from the stresses and form together with the supports the system of forces reacting upon the rock displacement. In this case, the contour deformation caused by the shattering, occur before support setting. Therefore, from this point of view, drilling and blasting method of working is more favorable than the cutting one.

It is known that stable rocks when the stresses do not exceed lasting properties of rocks and the deformation is of elastic kind, the contour is stable and the support and the bearing structure are not needed. In those cases when there is the inelastic deformation area around the working, it is necessary to set the compressible support to provide the rock with the possibility of some deformation, otherwise the support can be destroyed.

When considering the system "support rock mass" in various geological conditions, we outlined two main support modes: the mode of given load and the mode of interdependent deformation (the support and the rock mass act together, the load on the support is determined by its deformation with deformed rock masses). The main support parameters are its compressibility and load-bearing capacity. These modes can be mixed and combined. For example, first the support can only support the exfoliated rocks of the roof and operate in the mode of given load, and then due to the rise of deformation of the overlying layers can 
be switched to the mode of interdependent deformation.

Years of experience in studying the mechanism of interaction of the system "support - rock mass" have given the opportunity to form the basic requirements for mine support, which are the following:

- To ensure the shape keeping and the cross section dimensions of the working throughout its operation time;

- Not to require an increase in the working cross section in the course of its construction and operation;

- To have a low resistance to the movement of the air flow when airing;

- To have a minimum cost of its construction and maintenance.

Taking into consideration the facts given above, we have developed some support options for the construction of mine workings in various conditions.

Currently the roof bolting of various modifications is widely used. The disadvantage of the known roof bolting structures is that they perform only one function - the role of the supporting structure that supports a specific rock mass of the marginal space of mine workings. However, while mining we meet various conditions of rock occurrence - bedding, fracture, multiple degree of disturbance. If the production is carried out using drilling and blasting operations, the 1.0-1.5 $\mathrm{m}$ depth rock-fracture zone is created within the marginal rock mass due to the explosion energy, and it significantly reduces the self-sustainability of rock outcrops.

In such cases it is necessary to create conditions for the stabilization of the geological structure of the rock mass behind the contour of the working. This is the second function that the roof bolting must have. Such a function, to some extent, should be performed by pre-stressed rope bolts rope. But the significant drawback in such constructions is the complexity of the multi-layer metal rope tensioning when installing bolts. We have developed a fundamentally new bolting type expanding hold-down [1], which consists of a metal rod 1 (Fig. 1), 2 metal wedge inserted into the slot on the upper end of the metal rod, two ribbed half-couplings 3, 4 connected by mounting ring (fixing device may have any other structure). The spring 5 , the design parameters of which are taken depending on the length of the bolt and the structural state of the rock mass, is fixed on metal rod 1.

The cylindrical sleeve 6 is fixed to the lower end of the spring. The cylindrical sleeve 6 has the thread on the outer surface on which there is the support plate 7 in contact with the rock mass 8 and tensioning nut 9.
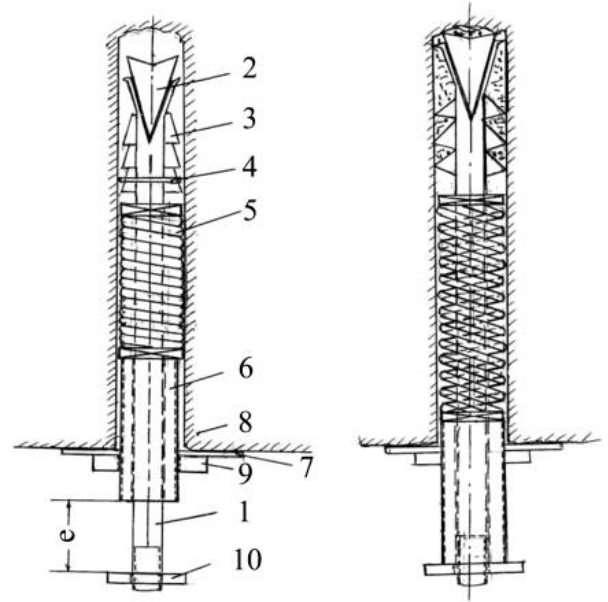

Fig. 1. Expanding hold-down bolt At the lower end of the metal rod the restrictive nut 10 is set by a threaded connection. The restrictive nut fixes the 
stretching length of the spring 5 and limits the move of the cylindrical sleeve 6 . The magnitude of the limiting distance $L$ is calculated when developing the plan of rock outcrop supporting, taking into account the structural condition of the rock mass and the magnitude of the required "contraction" of it depending on the degree of fracturing and disturbance.

The anchor is inserted into the hole and fixed with a metal wedge 2 and ribbed half-couplings 2 and 3 at the bottom of the hole. For a more durable fixing of the head part of the bolt the polyester resins ampoules were used. After fixing the bolt in the hole, the tensioning nut 9 is screwed onto a cylindrical sleeve 6 , which is shifted along a metal rod 1 to the lower position as far as the restrictive nut 10, stretching the spring, while pressing the support plate against the supported rock mass.

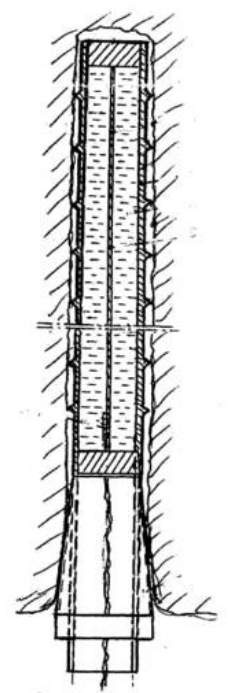

Fig. 2. Hydroexplosive tubular anchor During the operation, a stretched spring tending to compress compresses broken rock layers, reducing cracks and preventing their further development, which greatly increases the stability of rock outcrops throughout the operation time of mine workings.

In the construction of mine workings in inmonolithic rocks undisturbed by fractures hydroexplosive tubular anchor is recommended (Fig. 2) [2]. It is made in the form of a metal pipe on the outer surface of which the jagged juts are situated.

The ends of the tube are closed with sealing plugs, and the interior of the tube is filled with water, detonating cord with EB passing through it.

Preliminary anchor fixing in the hole until the moment of detonating cord initiation is made by means of special flare nut [3].

After placing hydro explosive tubular anchors in the holes the electric detonators are ignited.

Upon the detonation of the detonating cord in the water, a hydraulic shock occurs and the compressive stresses act on the metal pipe walls throughout its length. Due to this, the wall of a metal pipe expand and press against the rock, but the jagged juts incorporate into the hole walls, providing effective and reliable fixation of the anchor in the hole.

In combination with constant roof bolting of any design, we have developed a temporary enclosed support (Fig. 3 and 4) $[4,5,6]$.

The aim of temporary enclosed support protection from rock piece falls after the explosion of the set of blast-hole charges in the course of shattered rock loading and face area treatment until the temporary and permanent support setting. This support consists of a sliding cantilever beams manufactured from special profile SVP with protective overlap in the form of a metal grate, fixed 


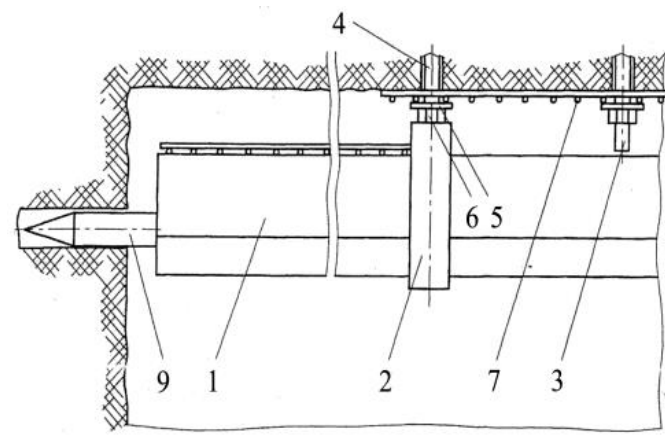

Fig. 3. Sliding temporary enclosed support

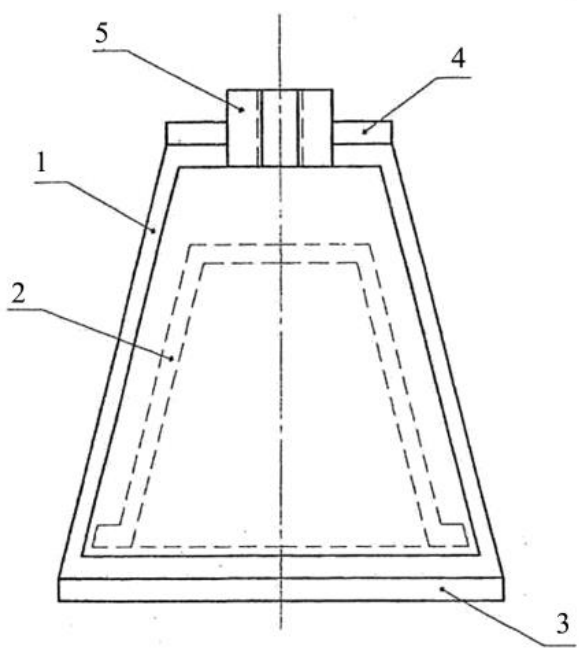

Fig. 4. Support element for sliding support

On the end parts of roof bolting with special support elements is made of bent parts in the form of a trapezoid, and repeats the shape of cantilever beams manufactured from special profile SVP. The bent parts are connected by horizontal upper and lower platforms. The upper platform has a nut screwed onto the cap wires of the bolting. The support elements are screwed and easily transferred to the following series of newly installed bolts.

The sliding temporary enclosed support is easily erected on the roof bolting and moves without any mechanisms, and the form of support elements, repeating the form of SVP cantilever beams prevent their displacement and inversion during the operation, which increases the safety of the miners.

\section{Conclusion}

The application of the designed lightweight kinds of supports allows reducing the material consumption and the cost of mine workings ensuring the required bearing capacity of the system "support - rock mass" and safety of miners.

\section{References}

[1] Patent № 138709, Russia, МПК Е21D 21/00. Expanding hold-down bolt / Yu.A. Masaev, V.Yu. Masaev, S.A. Sokolov. Published 20.03.2014.

[2] Patent № 122697, Russia, МПК Е21D 21/00. Hydroexplosive tubular anchor / Yu.A. Masaev, V.V. Pershin, V.Yu. Masaev, E.V.Kurekhin. Published 10.12.2012.

[3] Patent № 128243, Russia, МПК Е21D 20/00. Device for preliminary hydroexplosive tubular anchor fixing in the borehole / Yu.A. Masaev, V.Yu. Masaev. Published 20.05.2013.

[4] Patent № 76073, Russia, МПК Е21D 19/04. Temporary enclosed support when constructing permanent roof bolting / S.N. Bakanyaev, E.V. Parshikova, Yu.A. Masaev, M.D. Voitov. Published 10.09.2008.

[5] Patent № 102679, Russia, МПК Е21D 19/00. Temporary enclosed support / V.V. Pershin, Yu.A. Masaev, M.D. Voitov, V.Yu. Masaev, E.V. Parshikova. Published 10.03.2011.

[6] Patent № 107282, Russia, МПК Е21D 19/00. Support element for sliding support / Yu.A. Masaev, V.Yu. Masaev, E.V. Parshikova. Published 10.08.2011. 